\title{
Conceição Evaristo: escrevivências do corpo ${ }^{1}$
}

\author{
Conceição Evaristo: escrevivências del cuerpo \\ Conceição Evaristo: escrevivências of the body
}

\author{
Viviani Cavalcante de Oliveira Leite ${ }^{2}$ \\ Edgar Cézar Nolasco 3
}

\begin{abstract}
Resumo
Este trabalho tem por objetivo refletir e teorizar acerca de algumas noções presentes na vida e obra da escritora mineira Conceição Evaristo. A saber, memória (AMARAL, 2000), arquivo (DERRIDA, 2001), sensibilidade (MIGNOLO, 2003) e sensibilidades biográficas (NOLASCO, 2010). Para tanto, valeremo-nos do conto de Evaristo "Macabéa, Flor de Mulungu" a fim de ilustrarmos a reflexão proposta. Dessa maneira, as noções supracitadas serão embasadas nos pressupostos da crítica biográfica e crítica biográfica fronteiriça desenvolvidas respectivamente pelos intelectuais Eneida Maria de Souza e Edgar Cézar Nolasco. Por fim, almejamos considerar em nossa leitura, o bios e o lócus do sujeito bem como sua (in)corporação nas produções literárias e intelectuais, partindo da premissa de que com/no corpo é que se dão as "sensibilidades biográficas".
\end{abstract}

Palavras-Chave: Conceição Evaristo; memória; arquivo; corpo; sensibilidades biográficas.

\section{Resumen}

Este trabajo tiene por objetivo reflexionar y teorizar acerca de algunas nociones presentes en la vida y obra de la escritora minera Concepción Evaristo. A saber, memoria (AMARAL, 2000), archivo (DERRIDA, 2001), sensibilidad (MIGNOLO, 2003) y sensibilidades biográficas (NOLASCO, 2010). Para ello, valiéramos del cuento de Evaristo "Macabéa, Flor de Mulungu" a fin de ilustrar la reflexión propuesta. De esta manera, las nociones arriba citadas se basan en los presupuestos de la crítica biográfica y crítica biográfica fronteriza desarrolladas respectivamente por los intelectuales Eneida Maria de Souza y Edgar Cézar Nolasco. Por último, anhelamos considerar en nuestra lectura, el bios y el locus del sujeto así como su (in) corporación en las producciones literarias e intelectuales, partiendo de la premisa de que con / en el cuerpo es que se dan las "sensibilidades biográficas".

Palabras claves: Conceição Evaristo; memoria; presentar; el cuerpo; sensibilidades biográficas.

\begin{abstract}
The purpose of this essay is theorizing about some considerations on the writer ConceiçãoEvaristo's life and work. Those considerations pass through memory (AMARAL, 2000), archive (DERRIDA, 2001), sensibilities (MIGNOLO, 2003) and biographic sensibilities (NOLASCO, 2010). In this way, we will take the Evaristo's short story "Macabéa, Flor de Mulungu" to illustrate the purposed discussion. Therefore, those concepts will be based on CríticaBiográfica and CríticaBiográficaFronteiriça developed by, respectively, the intellectuals Eneida Maria de Souza and Edgar Cézar Nolasco. Finally, we expect to consider, throughout our read, the subjectbios and locus and their (in)corporation on Evaristo's literary and intellectual productions, taking as premise that the biographic sensibilities happen with/in the body.
\end{abstract}

\footnotetext{
1 Artigo apresentado no Simpósio Temático (NOME DO SIMPÓSIO TEMÁTICO) durante o II Seminário Latino-Americano de Estudos em Cultura - SEMLACult em Foz do Iguaçu/PR, Brasil, 2018.

2 (Pós- graduanda; Programa de pós-graduação mestrado em estudos de linguagens - UFMS; Campo Grande; MS, Brasil; vivianicoleite@ hotmail.com.

${ }^{3}$ Professor Doutor de teoria da Literatura; Universidade Federal de Mato Grosso do Sul; Campo Grande, MS, Brasil; ecnolasco@uol.com.
} 
Keywords: ConceiçãoEvaristo; memories; archive; body; biographic sensibilities.

\section{Introdução}

A escritora mineira Conceição Evaristo cunhou o termo "escrevivência" para representar sua própria escrita e as escritas das mulheres negras na literatura. O termo criado pela intelectual é a junção das palavras "escrever" e "viver", portanto está ligado a ideia de uma escrita contaminada com a subjetividade da escritora. Sua obra é marcada pela crítica social, pela história dos afrodescendentes, pela ancestralidade e por profundas reflexões sobre raça e gênero. Em entrevista ao jornal O Globo (2016), Evaristo afirma: “- Eu sempre tenho dito que a minha condição de mulher negra marca a minha escrita, de forma consciente inclusive. Faço opção por esses temas, por escrever dessa forma. Isso me marca como cidadã e me marca como escritora também."Deparamo-nos então com um projeto literário profundamente marcado por seu bios e por suas memórias. Assim, pensando o conceito de "escrevivência" cunhado pela intelectual Conceição Evaristo enquanto um jogo de representações biográficas, valeremo-nos dos pressupostos da crítica biográfica, de natureza compósita, como afirma Souza:

A crítica biográfica por sua natureza compósita, englobando a relação complexa entre obra e autor, possibilita a interpretação da literatura além de seus limites intrínsecos e exclusivos, por meio da construção de pontes metafóricas entre o fato e a ficção (SOUZA, 2002, p. 111).

Nesta perspectiva, a reflexão para a qual nos propomos é construir tais pontes por meio dessa linha de estudos que transita entre as extremidades do real e da ficção, englobando assim um estudo tanto do texto literário como do que diz respeito ao autor. Assim permitiremo-nos refletir não apenas a cerca dos textos literários de Conceição Evaristo, como também de seus bios, ampliando assim as possibilidades de minha leitura e a inserção do meu bios, uma vez que, como afirma o crítico Edgar Cézar Nolasco, a quebra de paradigma de maior impacto da crítica biográfica nessa virada de século foi "a inserção da figura do intelectual no ensaio crítico, a presença mesma de sua persona"(NOLASCO, 2010, p.35). Queremos então substituir o termo "inserção" utilizados pelo estudioso por "incorporação", metaforicamente falando, pois pensamos que com/no corpo é que se dão as "sensibilidades biográficas." Daí a justificativa para a expressão "escrevivência do corpo" do qual nos referimos no título deste texto. Ainda na esteira de Nolasco

O processo transculturador, demandado pela cultura fronteiriça e suas histórias locais híbridas situadas entre lá e cá, cria um entre-lugar (SANTIAGO) cultural povoado de sensibilidades biográficas de afetos e de memórias subalternas que transitam entre o local e o global sem culpas (NOLASCO, 2013, p. 129).

Nossa leitura partirá desse entre lugar no qual nos inscrevemos para refletir a cerca das sensibilidades biográficas, que é de suma importância, em especial no que diz respeito à Conceição Evaristo, uma escritora negra de origem humilde que nasceu e cresceu em uma 
favela da zona Sul de Belo Horizonte e que enfrentou inúmeras dificuldades, conciliando trabalho braçal e estudos, tornando-se professora, mestre e doutora em literatura.

Considerando as perceptíveis marcas do bios, da memória e inclusive da memória ancestral nas narrativas da escritora contemporânea, entendemos que a memória "está" ao invés de "esteve" presente na vida e obra de Evaristo, então a noção de arquivo emerge, ou seja, trata-se de uma memória ancestral que a partir do momento em que é (des)arquivada, deixa de ser passado e torna-se presente, mas um presente contínuo que lança para o futuro uma promessa um por vir. Amaral afirma a respeito da memória em Derrida, que

[...] isso que se costuma chamar de passado passa a ser presente quando a memória se torna narrativa no ato de lembrar e não mais guardar algo, sempre a partir e depois da inscrição, que será sempre promessa já a caminho do que está por vir. O que já aconteceu será sempre presente justamente atualizado através da memória tornada narrativa e o que está acontecendo pode-se apenas imaginar que no futuro será passado (AMARAL, 2000, p. 32).

Dessa maneira, por meio de um exercício arquiviolítico, constroem-se as memórias narrativas de Evaristo, ou seja, suas narrativas são concebidas a partir do corpo, um corpo presente que trás a tona as memórias do passado e as lançam para o futuro em forma de reescrita, a promessa/o por vir aqui é a reescrita da história do negro que outrora fora escrita numa perspectiva ocidentalista e excludente que ironicamente rechaçara o corpo negro de sua própria história. Como afirma o Filósofo Jacques Derrida:

A questão do arquivo não é, repetimos, uma questão do passado. Não se trata de um conceito do qual nós disporíamos ou não disporíamos já sobre o tema do passado, um conceito arquivável de arquivo. Trata-se do futuro, a própria questão do futuro, a questão de uma resposta, de uma promessa e de uma responsabilidade para amanhã (DERRIDA, 2001, p. 50, grifos do autor).

Podemos compreender que as questões do arquivo estão intrinsecamente relacionadas ao projeto literário e intelectual de Conceição Evaristo, pois através de sua escrevivência levanta questionamentos cujas respostas incitam uma reflexão social. Esta é a responsabilidade do intelectual tal qual conceitua Edward W. Said ao afirmar que o intelectual é um sujeito detentor do dom de "representar, dar corpo e articular uma mensagem, um ponto de vista, uma atitude filosofia ou opinião para (e também por) um público" (SAID, 2005, p. 26). 
Para empreender a leitura para a qual nos propomos, selecionamos o conto "Macabéa, Flor de Mulungu" (2012) de Conceição Evaristo, trata-se de uma releitura da última obra publicada em vida de Clarice Lispector, no qual a escritora contemporânea recria a miserável e virgem jovem alagoana, fazendo-a (re)nascer em flor de mulungu trinta e cinco anos após a ascensão da estrela. No conto é possível perceber nitidamente uma representação literária em que se estende a denúncia social realizada na novela, entretanto a escritora contemporânea agrega a representação de um grupo. Conceição Evaristo nega a fraqueza, a insignificância e principalmente a morte da personagem Macabéa agregando através dessa negação a representação de um grupo. Como podemos ler no fragmento abaixo:

Flor de Mulungu tinha a potência da vida. Força motriz de um povo que resilientemente vai emoldurando seu grito. Mulheres como Macabéa não morrem. Costumam ser porta-vozes de outras mulheres, iguais a elas, mesmo que travestidas em Glórias, e também costumam ser intérpretes das dores de homens, cabrasmachos, vítimas-algozes, como Olímpico de Jesus. Macabéa não ia morrer. Uma trindade feminina potencializa a existência dela. Macabéa, mulher das mezinhas, dos cerzimentos, das mãos aparadoras e anunciantes da boa-nova do nascimento da vida, não morreria jamais (EVARISTO, 2012, p. 20 - 21).

Em resumo, buscamos neste texto, desenvolver uma reflexão, relacionando os conceitos de "memória","sensibilidades biográficas" e "arquivo", embasados nos pressupostos da crítica biográfica, visto que ambicionamos considerar em nossa leitura o bios e o lócus da escritora Conceição Evaristo bem como sua (in)corporação em seu projeto literário e intelectual.

$\mathrm{O}$ ato de abrir o arquivo nos ajuda a pensar melhor as produções literárias e intelectuais de Conceição Evaristo, ao passo que recuperamos as histórias e memórias que atravessam a vida e obra da escritora. Para isso, partimos das imagens "da árvore" e, principalmente, da flor de mulungu, pois através delas podemos construir as pontes metafóricas necessárias para nossa leitura.

\section{Escrevivência: a pena do corpo}

A nossa escrevivência não pode ser lida como histórias para "ninar os da casa grande" e sim para incomodá-los em seu sonos injustos.

Conceição Evaristo.

Com o advento dos Estudos culturais, a literatura perde seu posto de entidade autossuficiente e os estudos literários deixam de ser de cunho exclusivamente literário e passam a ser vistos enquanto objeto cultural assumindo assim um caráter interdisciplinar que agrega elementos externos como, por exemplo, os elementos biográficos, ideológicos e históricos. 
Desde então, a crítica biográfica, muito estudada pela intelectual Eneida Maria de Souza, tem se aplicado em investigar a relação obra e vida não motivada por razões estritamente literárias, mas por razões culturais. Dessa maneira, essa teoria não se detém apenas no material literário, mas "ao escolher tanto a produção ficcional quanto a documental do autor [...] desloca o lugar exclusivo da literatura como corpus de análise e expande o feixe de relações culturais" (SOUZA, 2002, p. 112).

Refletir acerca do termo "escrevivência" é muito pertinente para ilustrar essa discussão que será fundamentada na crítica biográfica. Como já dissemos, trata-se de um conceito cunhado pela escritora mineira Conceição Evaristo para referir-se a sua própria escrita e à escrita de outras mulheres negras. Segundo Evaristo a escrevivência "é uma escrita que se dá colada à nossa vivência, seja particular ou coletiva" (LIMA, 2017, s/p), assim, nas palavras da intelectual Conceição Evaristo:

[A escrevivência] seria escrever a escrita dessa vivência de mulher negra na sociedade brasileira. Eu acho muito difícil a subjetividade de qualquer escritor ou escritora não contaminar a sua escrita. De certa forma, todos fazem uma escrevivência, a partir da escolha temática, do vocabulário que se usa, do enredo a partir de suas vivências e opções. A minha escrevivência e a escrevivência de autoria de mulheres negras se dá contaminada pela nossa condição de mulher negra na sociedade brasileira. Toda minha escrita é contaminada por essa condição. É isso que formata e sustenta o que estou chamando de escrevivência (LIMA, 2017, s/p).

Nesse sentido, a escrevivência é um conceito, cunhado pela intelectual mineira para definir ou nomear a "escrita de si" ou auto(biografia)ficção da mulher negra na literatura brasileira. Em Janelas indiscretas, Souza afirma que a crítica biográfica contemporânea "consiste na possibilidade de reunir teoria e ficção, considerando que os laços biográficos são criados a partir da relação metafórica existente entre obra e vida" (SOUZA, 2011, p. 21).

Assim, podemos entender que o termo "escrevivência" é concebido enquanto um conceito teórico, uma metáfora que representa essa relação vida e obra muito presente na literatura de Evaristo. Dessa maneira, a natureza heterogênea da crítica biográfica nos permite relacionar o termo da intelectual (teoria/vida) à sua escrita literária (obra/vida).

Ora, a epígrafe que inicia esse subtítulo, não é um texto literário, trata-se de uma fala muito recorrente nos discursos da escritora, no entanto, tenho a liberdade de trazê-lo à nossa reflexão por meio da crítica biográfica que nos permite essa movimentação do público e/ao privado concomitantemente. Vale ressaltar que nessa epígrafe há uma marca de intertextualidade com a história das mulheres escravas que ninavam os filhos das senhoras da "casa grande"; esse recurso (intertextualidade) também é muito comum nas narrativas literárias da escritora: 
E por força de antigos conhecimentos, adivinhei a dor da moça. E de que viver, o que escrever se não sangrassem em mim a dor da estrela? E não sei por que, em hora tão imprópria Flaubert me veio à cabeça. Depois atinei com o porquê da visita do francês ao meu pensamento. Se ele, para se defender da severa moral da época, precisou afirmar que Emma Bovary era ele, eu não preciso de nenhum ardil para garantir que Macabéa, a Flor de Mulungu, sou eu. Tal é a minha parecença-mulher com ele. Repito, sou eu e são todos os meus (EVARISTO, 2012, 16 - 17).

Ao pensar a "escrevivência" por via de uma noção semântica, a entendê-la como uma junção das palavras "escrever" e "vivência", que significa, grosso modo, representar a vida pela escrita, ou, à luz da crítica biográfica, construir pontes metafóricas entre vida e obra, por meio da escrita.

As muitas discussões a respeito da escrita de si trazem em seu escopo os polêmicos termos biografia, autobiografia, autoficção e bioficção. Quero aqui me deter primeiramente nos dois primeiros, pois o terceiro será desenvolvido no segundo capítulo, visto que percebo no decorrer de minha leitura uma certa divergência entre alguns teóricos ao estabelecer o termo mais acertado para nomear o conceito de tal escrita. Em Escritas de si, escritas do outro (2012) Diana Klinger afirma que

Na definição de autobiografia de Fhilippe Lejeune (1996), o que diferencia a ficção da autobiografia não é a relação que existe entre os acontecimentos da vida e sua transcrição no texto, mas o pacto implícito ou explícito que o autor estabelece com o leitor, através de vários indicadores presentes na publicação do texto, que determina seu modo de leitura. Assim, a consideração de um texto como autobiografia ou ficção é independente do seu grau de elaboração estilística (KLINGER, 2012, p. 10)

Entendemos, assim, que a crítica se baseia em uma ideia de pacto autobiográfico entre autor e leitor. Por outro lado, Eneida Maria de Souza afirma que Serge Doubrovisk demonstra uma certa intenção de aliviar o autor de tal pacto ao defender como melhor conceito a autoficção, que em sua perspectiva "é a forma pós-moderna, quer dizer, pós-holocausto, da autobiografia" (SOUZA, 2011, p. 22) na qual afirma que o relato só pode ser lido enquanto texto e não enquanto vida:

Uma vez mais, nenhuma autobiografia, nenhuma autoficção pode ser a fotografia, a reprodução de uma vida. Não é possível. A vida se vive no corpo; a outra é um texto. (...) a autoficção é o meio de ensaiar, de retomar, de recriar, de remodelar num texto, numa escrita, experiências vividas de sua própria vida que não são de nenhuma maneira uma reprodução, uma fotografia...É literalmente e literariamente uma invenção (DOUBROVSK apud SOUZA, 2011, p. 22).

Tal afirmação de Doubrovsky, de certa maneira, tem um sentido oposto ao empreendido em nossa reflexão, pois acrediamos que o corpo, a vida e a escrita de certa maneira estão incorporados em tal invenção referida pelo teórico, por isso nossa defesa em relação à escrevivência da intelectual Conceição Evaristo. 
Isso não significa que nossa posição seja em defesa de uma verdade biográfica reproduzida no ato literário, longe disso; em se tratando de leituras referentes a autobiografias, ou melhor dizendo, de autoficções, não pretenemos investigar a veracidade do acontecimento narrado mas o que propomos "é considerar o acontecimento - se ele é recriado na ficção desvinculado de critérios de julgamento quanto à veracidade ou não dos fatos." (SOUZA, 2010, p. 54).

Desse modo, em nossa condição de críticos biográficos e em nosso lócus enunciativo fronteiriço, acreditamos que não há, como já dito, possibilidade de se excluir o corpo das produções teóricas, críticas e literárias. Posto que consideramos que as sensibilidades biográficas, tanto do sujeito biografado quanto do crítico biográfico, se dão com e no corpo, de outro modo, pensamos que a autoficção se escreve/vive no/com o corpo. Segundo Souza:

[...] é necessário distinguir e condensar os polos da arte e da vida, através da utilização de um raciocínio substitutivo e metafórico, com vistas a não naturalizar e a reduzir os acontecimentos vivenciados pelo escritor. A preservação da liberdade poética da obra, na reconstrução de perfis biográficos, consiste no procedimento de mão dupla, ou seja, reunir o material poético ao biográfico, transformando a linguagem do cotidiano em ato literário (SOUZA, 2010, p. 53).

Nesta perspectiva, podemos inferir que a crítica biográfica amplia o corpus no intento de estudar um campo discursivo no qual a obra e seu autor se inscrevem. Dessa maneira, emerge também uma relação transferencial que se dá entre crítico biográfico e biografado, na qual o primeiro "aceita o desafio de pensar as relações de amizade para além das amizades propriamente ditas, do bios para além do bios" (NOLASCO, 2010, p. 50).

Esta relação permite ao crítico biográfico construir pontes metafóricas entre a vida e obra do objeto de estudo e a sua própria vida, assim "resta ao crítico biográfico pôr-se na condição de sujeito suposto saber: deste lugar, ou condição, ele imagina saber os segredos da vida do outro, inclusive aquilo que o outro mesmo não sabe sobre sua vida" (NOLASCO, 2010, p. 44). Em Perto do coração selbaje da crítica fronteriza (2013), Nolasco parte da noção de "sensibilidades locais" proposta por Walter Mignolo para cunhar a noção de "sensibilidades biográficas". O crítico afirma:

[...] ao me propor pensar a partir da periferia, descubro, para minha surpresa, que há periferias dentro da periferia e que pensá-las, por sua vez, demanda uma perspectiva crítica ainda mais específica, como forma de abarcar suas especificidades e suas sensibilidades biográficas (NOLASCO, 2013, p. 97).

Nesta perspectiva emergem então de dentro das senbilidades locais as sensibilidades biográficas, dito de outro modo, a sensibilidade das sensibilidades. Se no livro de 2013 supracitado, o intelectual atenta para a existência da sensibilidade biográfica que, por sua vez, 
dialoga com a crítica biográfica, na edição de 2015, dos CADERNOS DE ESTUDOS CULTURAIS, em seu texto "CRÍTICA BIOGRÁFICA fronteiriça (BRASILIPARAGUAIIBOLÍVIA)" o crítico cunha a rubrica "Crítica biográfica fronteiriça" a qual o crítico passa a denominar de:

[...] (bios=vida + lócus=lugar) biolócus. Por essa conceituação compreendo, então, a importância de se levar em conta numa reflexão crítica de base fronteiriça tanto o que é da ordem do bios (quer seja do "objeto" em estudo, quanto do sujeito crítico envolvido na ação), quanto da ordem do lócus (o lugar a partir de onde tal reflexão é proposta) (NOLASCO, 2015, p. 50).

Assim, a concepção de Crítica biográfica fronteiriça cunhada por Edgar Cézar Nolasco foi proposta a partir das teorias emergidas dos estudos pós-ocidentais/póscoloniais/descoloniais e da crítica biográfica. Com efeito, tal concepção transita pelos entrelugares fronteiriços no/do qual construo minha teorização, pois me permitem pensar meu biolócus enquanto intelectual crítico fronteiriço. Assim, podemos entender que o intelectual crítico fronteiriço é também um crítico biográfico fronteiriço que, ao escolher por aprender a desaprender (des)constrói as teorias advindas do colonialismo e põe em prática uma teorização de opção descolonial pensada a partir de seu biolócus.

A desobediência epistêmica posta em prática tanto pela razão pós-subalterna quanto pela opção descolonial dá-se não porque elas ignoram os conceitos modernos e as categorias que estão na base do pensamento ocidental, mas porque elas se predispuseram a des-aprender a lição canônica (tradição moderna) e aprender como se fosse pela primeira vez (NOLASCO, 2013, p. 8).

Dessa maneira, aprender a desaprender (MIGNOLO), implica em um processo de pensar/fazer descolonial libertador, no sentido de que liberta nossas mentes que "tinham sido programados pela razão imperial/ colonial" (MIGNOLO, 2008, p. 290). Dito de outro modo, trata-se de aprender a desaprender os conceitos impostos pela razão imperial/colonial e reaprender/reescrever nossas histórias que outrora foram lançadas ao limbo da colonialidade. E também um processo de desprendimento e de desobediência epistêmica para o qual nos dispusemos.

A razão subalterna/descolonial nasce em resposta desobediente ao princípio da filosofia descarteana que concebeu a razão moderna e negou a existência aos corpos fronteiriços por meio da afirmação de que era preciso pensar para existir. Dessa maneira, a exclusão do sujeito fronteiriço se deu de maneira contraditória, pois a epistemologia emerge, em contraproposta, para afirmar que pode sim o corpo fronteiriço pensar.e escrever sua própria história, ou melhor dizendo, sua vivência.

Entendemos que uma literatura concebida a partir de um corpo feminino negro como a de Conceição Evaristo somadas as suas sensibilidades biográficas nos proporciona um olhar 
mais amplo a respeito da história da mulher negra no Brasil e de sua trajetória na literatura brasileira. Dessa maneira, podemos compreender a diferença entre falar sobre e falar a partir $d e$, segundo propõe Walter Mignolo. Nesta perspectiva, diríamos: falar a partir do corpo feminino negro.

Isto não implica em uma defesa nossa à ideia de que apenas a mulher negra seja capaz de contar tal história e refletir sobre ela, o que sugerimos é "que aqueles para quem as heranças coloniais são reais (ou seja, aqueles a quem elas prejudicam) são mais inclinados (lógica, histórica e emocionalmente) que outros a teorizar o passado em termos da colonialidade" (MIGNOLO, 2003, p. 166).

Compreendemos que a história oficial da colonização, fora escrita em uma perspectiva global que, por consequência, excluiu as histórias locais e suas respectivas sensibilidades biográficas. Quando o sujeito ignora suas histórias locais, está fadado ao preconceito e a endossar e repetir o ciclo de exclusão que se formou no colonialismo, daí a importância da escrevivência.

A escrevivência de Conceição Evaristo não pode ser lida por outro viés que não seja o da desobediência epistêmica, visto que, apenas um pensamento descolonial pode dar conta de uma reflexão crítica a respeito de seu projeto literário e intelectual que, por sua vez, habita o efêmero espaço fronteiriço. Assim, enquanto sujeitos críticos fronteiriços, nossa leitura tem se desenvolvido por meio de um exercício arquiviolítico, segundo a concepção derridiana, pois, como já dito pelo filósofo, "o arquivo tem lugar em lugar da falta originária e estrutural da chamada memória" (DERRIDA, 2001, p. 22).

\section{Referências}

AMARAL, Adriana Corner lopes do. "Sobre a memória em Jacques Derrida". In: NASCIMENTO, Evandro; GLENADEL, Pula (Orgs). Em torno de Jacques Derrida. Rio de Janeiro: 7 Letras, 2000. p. 31-43.

CADERNOS DE ESTUDOS CULTURAIS. Crítica biográfica. Campo Grande-MS: Ed. UFMS, v. 2, n. 4, jul./dez. 2010.

DERRIDA, Jacques. Mal de arquivo: Uma Impressão Freudiana, Rio de Janeiro: Relume Dumará, 2001.

EVARISTO, Conceição. "Macabéa, Flor de Mulungu". In GUIMARÃES, Mayara R.; MAFFEI, Luis (Orgs.). Extratextos 1 - Clarice Lispector, personagens reescritos. Rio de Janeiro: Oficina Raquel, 2012. p. $13-21$. 
KLINGER, Diana. escritas de si, escritas do outro: o retorno do autor e a virada etnográfica/Diana Klinger. $3^{\text {a }}$ Ed. - Rio de Janeiro: 7Letras, 2012.

LIMA, Juliana Domingues de. Conceição Evaristo: 'minha escrita é contaminada pela condição de mulher negra'. NEXO. Disponível em: https://www.nexojornal.com.br/entrevista/2017/05/26/Concei\%C3\%A7\%C3\%A3o-Evaristo$\% \mathrm{E} 2 \% 80 \% 98$ minha-escrita-\%C3\% A9-contaminada-pela-condi\%C3\%A7\%C3\%A3o-demulher-negra\%E2\%80\%99. Acesso em 18.03.2018.

LISPECTOR, Clarice. A hora da estrela. Rio de Janeiro: Rocco, 1998.

MIGNOLO, Walter. Histórias locais/ projetos globais: colonialidade, saberes e pensamento liminar. Trad. de Solange Ribeiro de Oliveira. Belo Horizonte: Editora UFMG, 2003.

MIGNOLO, Walter. Desobediência epistêmica: A opção descolonial e o significado de identidade em política. In: Cadernos de Letras da UFF. Niteroi, n. 34. 2008. p. 287-324.

NOLASCO, Edgar Cézar. Perto do coração selbaje da crítica fronteriza. São Carlos: Pedro \& João Editores, 2013.

NOLASCO, Edgar Cézar. A razão pós-subalterna da crítica latina. In: CADERNOS DE ESTUDOS CULTURAIS: pós-colonialidade. Campo Grande, MS: Editora UFMS, v. 5, n. 9, jan./jun. 2013.

NOLASCO, Edgar Cézar. CRÍTICA BIOGRÁFICA fronteiriça (BRASILIPARAGUAIBBOLÍVIA). In: CADERNOS DE ESTUDOS CULTURAIS: Brasil/Paraguai/Bolivia. Campo Grande, MS: Editora UFMS, v. 7, n. 14, jul./dez. 2015.

NOLASCO, Edgar Cézar. Políticas da crítica biográfica. In: CADERNOS DE ESTUDOS CULTURAIS: crítica biográfica. Campo Grande, MS: Editora UFMS, v. 2, n. 4, set. 2010.

SOUZA, Eneida Maria de. Crítica biográfica ainda. In: CADERNOS DE ESTUDOS CULTURAIS: crítica biográfica. Campo Grande, MS: Editora UFMS, v. 2, n. 4, set. 2010.

SOUZA, Eneida Maria de. Crítica cult. Belo Horizonte: Editora UFMG, 2007.

SAID, Edward. Representações do intelectual. São Paulo: Companhia das letras, 2005. 